\title{
Effects of a Putty-Form Hydroxyapatite Matrix Combined With the Synthetic Cell-Binding Peptide P-15 on Alveolar Ridge Preservation
}

\author{
Rodrigo F. Neiva, * Yi-Pin Tsao, * Robert Eber, ${ }^{*}$ Jeffrey Shotwell, ${ }^{\dagger}$ Edward Billy, ${ }^{\dagger}$ and Hom-Lay Wang*
}

Background: Various grafting materials have been used for preservation of the dimensions of the residual alveolar ridge following tooth extraction. The purpose of this study was to evaluate clinical, histomorphometric, and radiographic healing 4 months after tooth extraction with or without placement of a putty-form anorganic bovine-derived hydroxyapatite matrix combined with a synthetic cell-binding peptide P-15 (Putty P15) to determine the effect on alveolar ridge preservation following exodontia.

Methods: Twenty-four consecutive subjects in need of extraction of maxillary premolars were recruited. Recruited subjects were randomly assigned to the test (Putty P15 and bioabsorbable collagen wound dressing material) or control (bioabsorbable collagen wound dressing material only) group. Data were recorded at $1,2,4,8$, and 16 weeks after ridge preservation procedures. At 16 weeks, a reentry surgery was performed, clinical measurements were repeated, and bone core biopsies were obtained for histomorphometric analysis prior to dental implant placement.

Results: The control group had a mean reduction in ridge height of $-0.56 \pm 1.04 \mathrm{~mm}$, whereas alveolar ridge height appeared to remain unchanged in the test group $(0.15 \pm$ 1.76). The test group showed a mean reduction in ridge width of $-1.31 \pm 0.96 \mathrm{~mm}$, whereas the mean value for the control group was $-1.43 \pm 1.05 \mathrm{~mm}$. No statistical significance was observed between the groups. Mean bone density was significantly superior in the test group $(2.08 \pm 0.65$ versus $3.33 \pm$ $0.65)$. Histomorphometric analyses revealed similar percentages of bone vitality (test: $29.92 \% \pm 8.46 \%$; control: $36.54 \% \pm$ $7.73 \%$ ). Comparable percentages of bone marrow and fibrous tissue also were observed (test: $65.25 \% \pm 6.41 \%$; control: $62.67 \% \pm 7.41 \%)$. Only $6.25 \%$ of the Putty P15 particles remained at 4 months in the analyzed biopsies.

Conclusion: A favorable response was observed when Putty P15 was applied to extraction sockets, suggesting that it may be useful for alveolar ridge preservation prior to dental implant placement. J Periodontol 2008;79:291-299.

\section{KEY WORDS}

Bone graft; dental implant; tooth extraction.

\footnotetext{
* Department of Periodontics and Oral Medicine, School of Dentistry, University of Michigan Ann Arbor, MI.

$\dagger$ Department of Biomaterials and Restorative Sciences, School of Dentistry, University of Michigan.
}

$\mathrm{T}$ ooth extraction results in atrophy of the edentulous alveolar ridge. ${ }^{1,2}$ This continuous process negatively influences dental implant placement as early as 4 months following exodontia. ${ }^{3-5}$ Reduction in alveolar ridge height and width may complicate or even prohibit optimal implant placement, often compromising esthetic and functional treatment outcomes. ${ }^{6}$ Techniques for preservation of alveolar ridge dimensions have been proposed and evaluated in the literature, ${ }^{7-12}$ and a variety of bone graft materials and barrier membranes have been suggested for their ability to enhance bone formation ${ }^{13-15}$ and their bone healing and bone-forming capacity in extraction sockets. ${ }^{16-20}$ However, to the best of our knowledge, the putty form of anorganic bovine-derived hydroxyapatite matrix combined with a synthetic cellbinding peptide P-15 (Putty P15) has not been evaluated for this purpose in a well-controlled, randomized clinical trial. Hence, this study was designed to test the ability of Putty P15 to function as bone graft material for alveolar ridge preservation following exodontia.

\section{MATERIALS AND METHODS}

The University of Michigan's Institutional Review Board reviewed and approved the research protocol for this doublemasked, randomized clinical trial. Using

doi: 10.1902/jop.2008.070038 
data from a previous study, ${ }^{21}$ a statistical power calculation indicated that 10 subjects per group would provide sufficient power $(0.80)$ to obtain statistical significance. To achieve maximum clinical significance, 24 consecutive subjects (12 test and 12 control) requiring extraction of maxillary premolars were selected from the patient pool of the School of Dentistry, University of Michigan. Subjects were enrolled from January 1, 2005 to April 30, 2005. Subject selection criteria included systemically healthy subjects with one maxillary premolar tooth requiring extraction and replacement by dental implant, residual extraction sockets with $<80 \%$ bone loss in all dimensions, presence of both adjacent teeth in a state of health, non-smokers, subjects willing and able to comply with all study-related procedures, including maintenance of good oral hygiene and compliance with reevaluation appointments, and subjects who read, understood, and were willing to sign an informed consent statement. Subjects with any of the following conditions were excluded from the study: inadequate band $(<2 \mathrm{~mm})$ of keratinized gingiva (KG) and/or buccal gingival recession $>2 \mathrm{~mm}$; presence of acute infections at the time of tooth extraction; clinically significant or unstable systemic diseases affecting bone or soft tissue growth or other renal, hepatic, cardiac, endocrine, hematologic, autoimmune, or acute infectious diseases; history of head and neck radiation therapy; subjects taking steroids, tetracycline or tetracycline analogs, bone therapeutic levels of fluorides, bisphosphonates, medications affecting bone turnover, or any investigational drug; or subjects who were or were planning to become pregnant during the length of the study. Recruited subjects were assigned randomly to receive Putty $\mathrm{P} 15^{\ddagger}$ and a bioabsorbable collagen wound dressing material§ (test group) or a bioabsorbable collagen wound dressing materiall only (control group). Customized acrylic templates were created with measuring slots to permit reproducible clinical measurements of the alveolar ridge dimensions.

The primary outcome variables evaluated included bone gain or loss in millimeters, percentage of bone formation in the alveolar bone core biopsies, the percentage of residual Putty P15 in the bone cores, and the need for additional bone grafting at the time of implant placement. Secondary outcome variables included soft tissue wound healing and the plaque index (PI), ${ }^{22}$ the gingival index $(\mathrm{GI}),{ }^{22}$ and clinical bone density on reentry, assessed during osteotomy preparation for implant placement. ${ }^{23}$

The following clinical measurements were made by a calibrated masked examiner (RE) at the baseline and reentry surgeries using standard University of North Carolina (UNC) manual probes: KG width and thickness; buccal plate thickness; distance from the occlusal template to the facial, lingual, and crestal bone; socket depth (or template to crest distance at the 4-month reentry surgery); and osseous dehiscence location and dimension. KG thickness was measured by probing through the gingiva at a point midway between the free gingival margin (FGM) and the mucogingival junction (MGJ). The width of KG was calculated as the distance between the FGM and the MGJ at the mid-facial aspect of the tooth to be removed at baseline and from the gingival crest to the MGJ at reentry. Bone topography was documented using the UNC probes and occlusal templates. Facial plate thickness was measured with a Boley gauge caliper at the mesio-distal midpoint of the socket $2 \mathrm{~mm}$ apical to the alveolar crest. Using the adjacent cemento-enamel junction or crown margins as reference points, osseous dehiscence defects were measured vertically from the mesio-distal midpoint of the socket to the apex of the defect and horizontally at the widest portion of the dehiscence using two perpendicular UNC probes. All measurements were rounded to the nearest $0.5 \mathrm{~mm}$.

Treatment randomization was achieved by having an uninvolved third party randomly fill 24 envelopes with a slip of paper indicating the treatment to be provided (12 test and 12 control). The envelopes were sealed, numbered sequentially, and returned to the primary investigator. To help minimize technical variances in the surgical treatment protocol, the primary investigator (RFN) performed the baseline and 4-month reentry surgeries. Under local anesthesia, the selected tooth was extracted with minimal trauma to the surrounding tissues, followed by degranulation of the socket and collection of all clinical measurements. Then the surgeon selected each numbered envelope in sequence and performed the treatment indicated. To prevent measurement bias, the examiner remained masked to the treatment provided throughout the study. In the test sites, Putty P15 was placed into each extraction socket to the level of the osseous crest. A bioabsorbable collagen wound dressing material ${ }^{\text {I }}$ was cut to a height $\sim 4 \mathrm{~mm}$ and placed to cover the remaining soft tissue height. The area was sutured with a modified cross-mattress technique (Fig. 1). The control sites received the same treatment with the exception of Putty P15 placement. A clot was allowed to form in the socket, and the collagen dressing material was placed over it to ensure that test and control sites would have a similar clinical appearance during postoperative appointments, preserving the masking of the examiner.

Soft tissue healing was assessed at 1, 2, 4, 8, and 16 weeks using a wound-healing index (WHI): $1=$ uneventful wound healing with no gingival edema,

\footnotetext{
† PepGen P-15 Putty, DENTSPLY Friadent Ceramed, Lakewood, CO.

$\S$ CollaPlug, Zimmer Dental, Carlsbad, CA.

II CollaPlug, Zimmer Dental.

If CollaPlug, Zimmer Dental.
} 
erythema, suppuration, discomfort, or Putty P15 exposure; 2 = uneventful wound healing with slight gingival edema, erythema, or discomfort, but minimal loss of Putty P15 and no suppuration; and 3= poor wound healing with significant gingival edema, erythema, discomfort, loss of Putty P15, or any suppuration. Reentry surgeries were performed at 16 weeks, and all clinical measurements were repeated (Fig. 2). Bone core biopsies $\sim 2.7 \times 10 \mathrm{~mm}$ in size were removed with a $3.2-\mathrm{mm}$ (outer diameter) trephine drill from the area corresponding to the center of the previous extraction socket using the occlusal template as a guide. Bone density also was recorded following final implant osteotomy preparation using a $4.5-\mathrm{mm}$ twist drill (Fig. 2). The cores were placed in bottles of $10 \%$ neutral buffered formalin for fixation and labeled with a five-digit number to permit masked histomorphometric analysis.

Photographs were taken of each bone core biopsy prior to processing. The cores were dehydrated in a series of graded alcohols and then embedded in glycol methacrylate. Each core was cut into $5-\mu \mathrm{m}$ sections, mounted on slides, and stained with hematoxylin and eosin. All sections were analyzed for the percentage of vital bone. Test sections also were analyzed for the percentage of remaining graft particles. An independent masked statistician performed the statistical analysis.
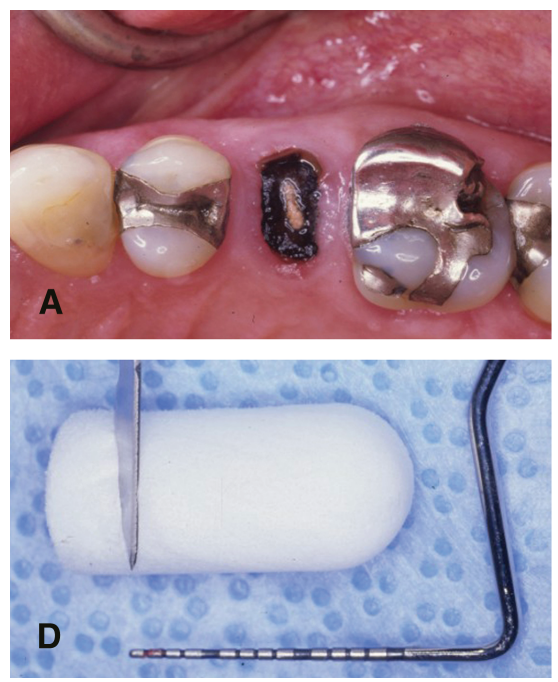
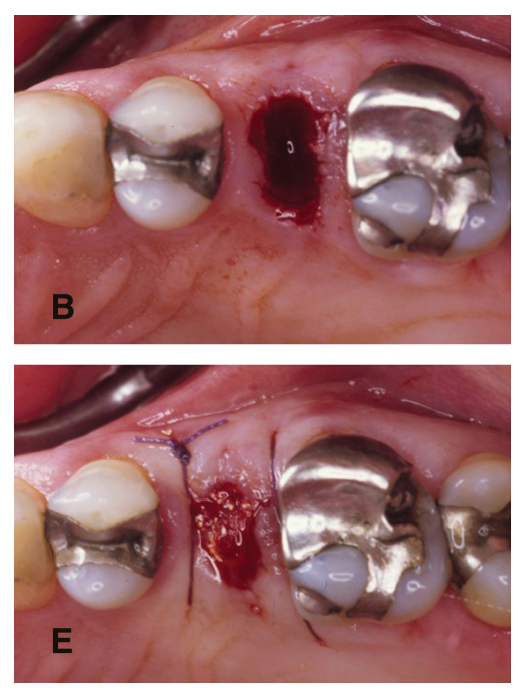
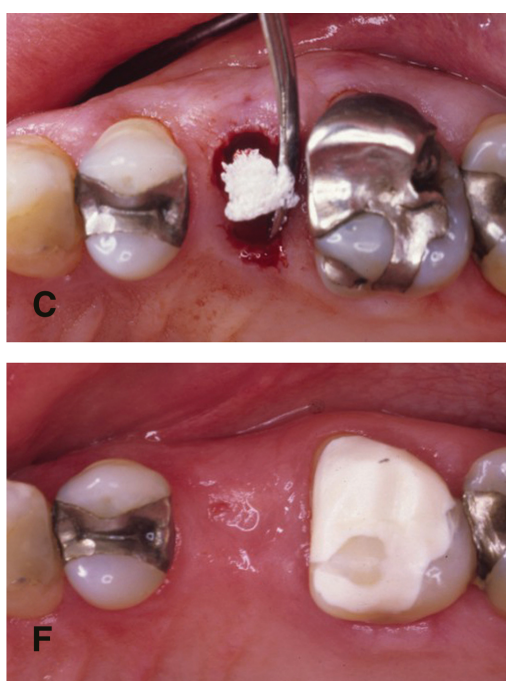

Figure I.

A) Hopeless maxillary premolar. B) Site following atraumatic exodontias. C) Placement of Putty PI 5 in the socket. D) Collagen dressing material was cut before placement. E) Cross-mattress suture. F) Postoperative healing at 30 days.
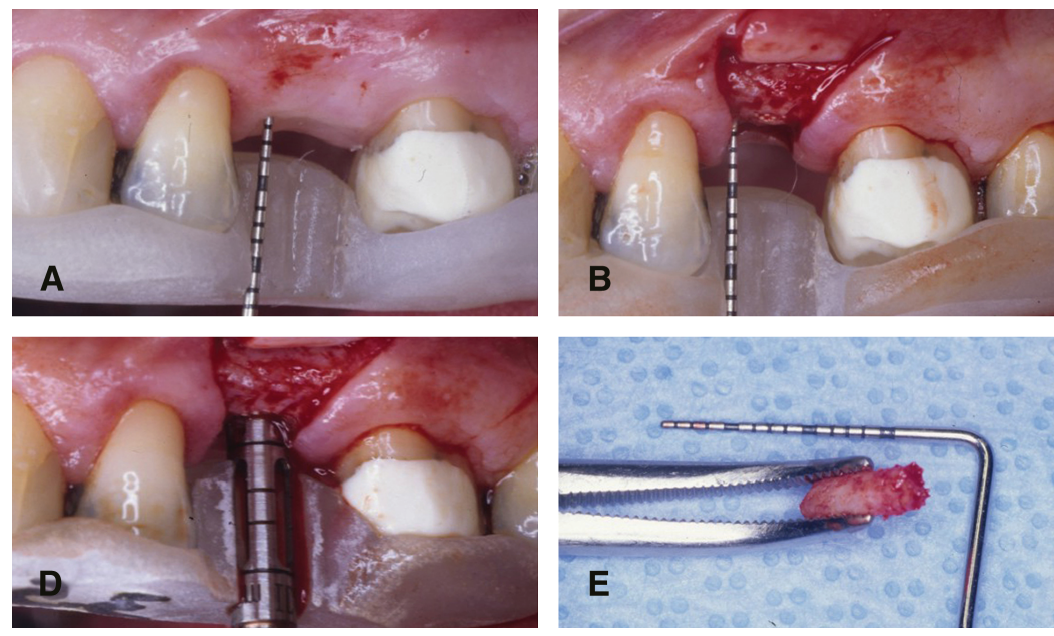
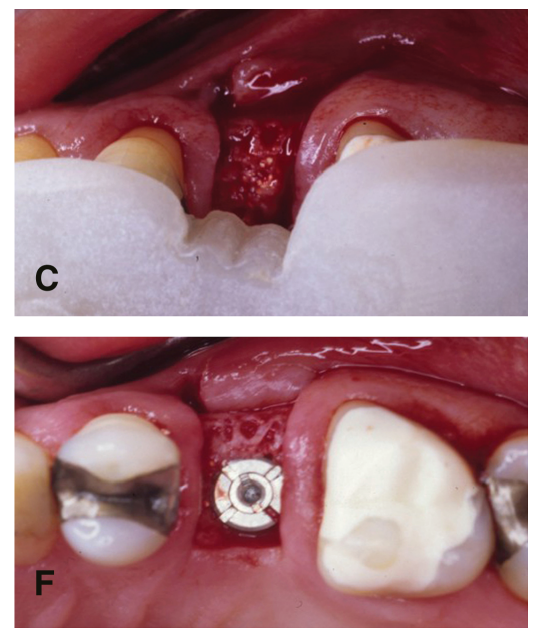

Figure 2.

A) Measurement of soft tissue height. B) Assessment of crestal ridge height. C) Identification of crestal bone width. D) Biopsy being harvested with trephine bur. E) Obtained core biopsy. F) Implant placement. 
The independent sample $t$ test and a two-tailed $t$ test with equal variance were used to determine statistical significance to a level of $P<0.05$.

\section{RESULTS}

\section{Demographics}

Table 1 lists demographic information for the study subjects. The mean age for test subjects was $48.00 \pm$ 14.89 years (range: 25 to 69 years of age), whereas control subjects had a mean age of $49.92 \pm 14.20$ years (range: 36 to 76 years of age).

\section{PI and GI (Table 2)}

Both groups began the study with comparable mean $\mathrm{PI}$ values (Table 2). A significant increase in PI values was observed at 7 and 14 days after surgery. At 60 and 120 days, both groups had values that were comparable to baseline values. A significant increase in GI values was observed at 7 days with a return to values comparable to baseline at 14 days after surgery. At 30 days, both groups exhibited a marked decrease, which continued to be observed at 60 and 120 days. No statistically significant differences were observed between the groups at any time point.

\section{WHI}

At 7 days post-surgery, mean values were $1.33 \pm 0.16$ (test) and $1.41 \pm 0.16$ (control). A statistically significant difference $(P=0.02)$ between the groups was observed at 14 days; the mean value for the test and control group was $1.00 \pm 0$ and $1.25 \pm 0.12$, respec-

\section{Table I.}

\section{Demographic Data of Study Population}

\begin{tabular}{lcc}
\hline & Test Group & Control Group \\
\hline Gender & & \\
Male $(\mathrm{N})$ & 7 & 6 \\
Female $(\mathrm{N})$ & 8 & 9 \\
Age (years; mean $\pm \mathrm{SD})$ & $48.00 \pm 14.89$ & $49.92 \pm 14.20$ \\
\hline
\end{tabular}

Table 2.

\section{PI and GI Values (mean \pm SD) in Test and Control Groups}

\begin{tabular}{ccccc}
\hline & \multicolumn{2}{c}{ Test Group } & \multicolumn{2}{c}{ Control Group } \\
\cline { 2 - 5 } & Baseline & 120 Days & Baseline & 120 Days \\
\hline PI & $0.97 \pm 0.32$ & $0.50 \pm 0.18$ & $0.84 \pm 0.30$ & $0.45 \pm 0.22$ \\
Gl & $0.58 \pm 0.22$ & $0.39 \pm 0.26$ & $0.66 \pm 0.22$ & $0.34 \pm 0.14$ \\
\hline
\end{tabular}

tively. A plateau was reached in both groups at 60 days when the WHI values at all sites returned to normal (test: $1.00 \pm 0$; control: $1.00 \pm 0$ ).

\section{Alveolar Ridge Width}

A comparable mean alveolar ridge width was observed between the groups at baseline. At 120 days, comparable atrophy of the edentulous ridge was observed. The test group showed a mean reduction in ridge width of $-1.31 \pm 0.96 \mathrm{~mm}$, whereas the mean value for the control group was $-1.43 \pm 1.05 \mathrm{~mm}$. No statistically significant difference was observed between the groups (Table 3).

\section{Alveolar Ridge Height}

A comparable mean alveolar ridge height was observed between the groups at baseline. At 120 days, a statistically significant difference was observed between the groups. The control group showed a mean reduction in ridge height of $-0.56 \pm 1.04 \mathrm{~mm}$, whereas alveolar ridge height appeared to remain unchanged in the test group $(0.15 \pm 1.76)$ (Table 3$)$.

\section{Bone Density}

The alveolar bone density that was assessed during final implant osteotomy preparation using Misch's bone density scale ${ }^{23}$ exhibited a statistically significant difference between the groups $(P=0.03)$. Mean bone density was significantly superior in the test group $(2.08 \pm 0.65)$ compared to the control group (3.33 \pm $0.65)$

\section{Need for Additional Grafting}

During implant placement, 33\% of the control sites demonstrated the need for additional bone grafting to allow for dental implants of adequate size in ideal positions and angulations. "Need for grafting" was defined as the presence of alveolar fenestration and/or dehiscences prior to or following implant osteotomy preparation. Conversely, no bone grafting was required in any site that had received Putty P15. The difference between the groups was statistically significant $(P=0.04)$.

\section{Residual Socket}

Although complete bone fill, represented by the presence of a flat and continuous ridge surface, was observed in all test sites 4 months following exodontia, $59 \%$ of the control sites had a residual socket. The difference between the groups was statistically significant $(P=0.03)$.

\section{Implant Primary Stability}

Although all implants placed in test sites achieved primary stability (100\%), one implant placed in a control site could not be stabilized because of reduced bone density, and placement had to be postponed. This resulted in primary stability in $91.77 \%$ of sites. A statistically significant difference was found between the groups. 
Table 3.

\section{Changes in Ridge Dimension From Baseline to 120 Days}

\begin{tabular}{lcc}
\hline & Test Group & Control Group \\
\hline Width $(\mathrm{mm})$ & $-1.31 \pm 0.96$ & $-1.43 \pm 1.05$ \\
Height $(\mathrm{mm})$ & $+0.15 \pm 1.76 *$ & $-0.56 \pm 1.04^{*}$ \\
\hline
\end{tabular}

* Statistical significance between baseline and observed time points.

\section{Histomorphometry}

Histomorphometric analyses revealed similar percentages of vital bone in the cores harvested during implant placement (test: $29.92 \% \pm 8.46 \%$; control: $36.54 \% \pm 7.73 \%$ ), which was assessed by the presence of osteoblasts in the lacunae. The difference between the groups was not statistically significant. Comparable percentages of bone marrow and fibrous tissue also were observed (test: $65.25 \% \pm 6.41 \%$; control: $62.67 \% \pm 7.41 \%)$. Again, no statistically significant difference was found between the groups. Only $6.25 \%$ of the Putty P15 particles remained at 4 months in the analyzed biopsies.

\section{DISCUSSION}

Bone healing and subsequent new bone formation after grafting take place via osteogenesis, ${ }^{24}$ osteoinduction, ${ }^{25}$ and/or osteoconduction. ${ }^{26}$ Osteogenic graft materials supply the viable osteoblasts that form new bone, whereas osteoinductive grafts stimulate pluripotential mesenchymal cells to differentiate into osteoblasts that can form new bone. However, osteoconductive graft materials merely act as a lattice for cell growth, permitting osteoblasts from the wound margins to infiltrate the defect and migrate across the graft. ${ }^{27}$ Autologous grafts are considered to be the ideal material for bone-grafting procedures. ${ }^{28}$ Transplantation of living cells increases the possibility of retained cell viability and graft revascularization. In addition, autologous grafts do not present a risk for disease transmission. ${ }^{29}$ However, they do increase the risk for additional pain, infection, and donor site morbidity. ${ }^{27}$ Bone substitutes have gained increasing acceptance as alternatives to autologous bone for patients requiring bone augmentation in an effort to decrease the cost and morbidity associated with autologous graft harvest. ${ }^{30}$ Allografts, xenografts, and alloplasts come in many forms, and data support their safety and clinical applicability ${ }^{31,32}$ and their low antigenicity. 33,34

Anorganic bone matrix (ABM), also known as hydroxyapatite, has become widely used as a bone xenograft based on its reported osteoconductive ca- pabilities. ABM permits rapid vascular and hard tissue ingrowth, and it may help to stimulate osseous regeneration without the need to harvest autologous bone from a second operative site. Alloplastic materials are another available form of bone replacement. Alloplasts are derived synthetically and also have been shown to possess osteoconductive properties. ${ }^{35} \mathrm{How}$ ever, xenografts and alloplasts lack osteoinductivity, a positive characteristic of allograft materials. ${ }^{36}$ Osteoinductive activity is believed to occur as a result of exposure of bone morphogenic proteins during the allograft demineralization process, ${ }^{37}$ because demineralized allografts are produced by acid extraction of the mineral components of bone. This process results in a graft material containing collagen, noncollagenous bone matrix proteins, and growth factors, but little residual bone mineral. ${ }^{37,38}$ In this way, demineralization exposes the bone-inductive proteins located in the bone matrix and may activate them. ${ }^{39}$ To promote cell attachment to ABM particles, the cell-binding peptide $\mathrm{P}-15$ has been added to its surface. P-15 is the cell-binding domain of collagen type I, which accounts for a third of the body's protein and interacts with many types of cells. The synthetic P-15 cell-binding peptide added to ABM provides a biomimetic environment and has been shown to differentiate a variety of fibroblasts (human dermal fibroblasts, gingival fibroblasts, and periodontal ligament fibroblasts) into bone-forming lineages, which promotes the normal physiologic processes leading to bone formation. ${ }^{40-44}$ Krauser et al. ${ }^{45}$ compared the results obtained with $\mathrm{ABM}$ and $\mathrm{ABM}+\mathrm{P}-15$ for maxillary sinus augmentation. Clinically, both grafted sinuses were similar in terms of granular appearance and density during osteotomy procedures. Each had a similar granular appearance and yielded equally under pressure during osteotomy procedures. However, histologic analyses revealed that sites treated with $A B M+P-15$ had new bone completely surrounding the graft particles, whereas the particles in ABM-treated sites remained encapsulated by a fibrous tissue. These findings suggested that $A B M+P-15$ had greater compatibility with the host bone tissue than ABM alone. This often leads to faster and more predictable bone maturation. Smiler $^{46}$ compared ABM plus demineralized freezedried bone allograft (DFDBA) to $A B M+P-15$ plus DFDBA for augmentation of maxillary sinuses. Four months after surgery, bone cores were obtained during osteotomies for placement of dental implants. Histologic analyses showed that $A B M+P-15$ was highly superior to $A B M$ alone when either one was combined with DFDBA for augmentation of maxillary sinuses. The combination of ABM + P-15 plus DFDBA showed $45 \%$ vital bone at 4 months, whereas ABM + DFDBA showed only $13 \%$. This xenograft also was shown to be safe for human use. ${ }^{47}$ 
Extraction sockets are considered a reliable model for evaluation of bone healing. ${ }^{48}$ Under normal circumstances, undisturbed extraction sockets show evidence of new bone formation within 30 days. ${ }^{49,50}$ To promote a fair comparison between groups, special attention was given in this study to site selection during subject recruitment. Only maxillary premolars were included to evaluate extraction sockets of similar size, bone quality, and anatomy, thus minimizing variables and strengthening the results obtained. Furthermore, trephine harvest location can be central to the extraction socket. This is particularly important because it allows for more accurate biopsy as well as placement of a dental implant in the ideal position. Bifurcated premolars did not seem to influence biopsy harvesting or analysis as a result of the more apical positioning of the interradicular septum in maxillary premolars. ${ }^{51}$ Because the trephine was inserted only to a depth of $8 \mathrm{~mm}$, the apical portion of the biopsy likely was coronal to the septum.

Alveolar ridge atrophy is an unavoidable sequela of tooth loss, and this phenomenon can interfere with ideal implant placement. ${ }^{1}$ Attempts to minimize ridge atrophy have been reported. ${ }^{19,20}$ Lekovic et al. $^{52}$ compared the outcome of alveolar ridge preservation using a bioabsorbable membrane to extraction alone. At 6 months, they found significantly less crestal bone loss $(-0.38$ versus -1.50 $\mathrm{mm})$, more internal socket fill $(-5.81$ versus $-3.94 \mathrm{~mm})$, and less horizontal ridge resorption $(-1.31$ versus $-4.56 \mathrm{~mm}$ ) in the membrane group than in the control. As this study suggested, successful alveolar ridge preservation procedures may reduce or eliminate the need for future ridge augmentation. Recent data published by Nevins et al. ${ }^{53}$ emphasized the significance of bone grafting following exodontia in preserving buccal plate integrity and in consequence, alveolar ridge dimensions for ideal implant treatment. Data

Figure 3.

Figure 4.
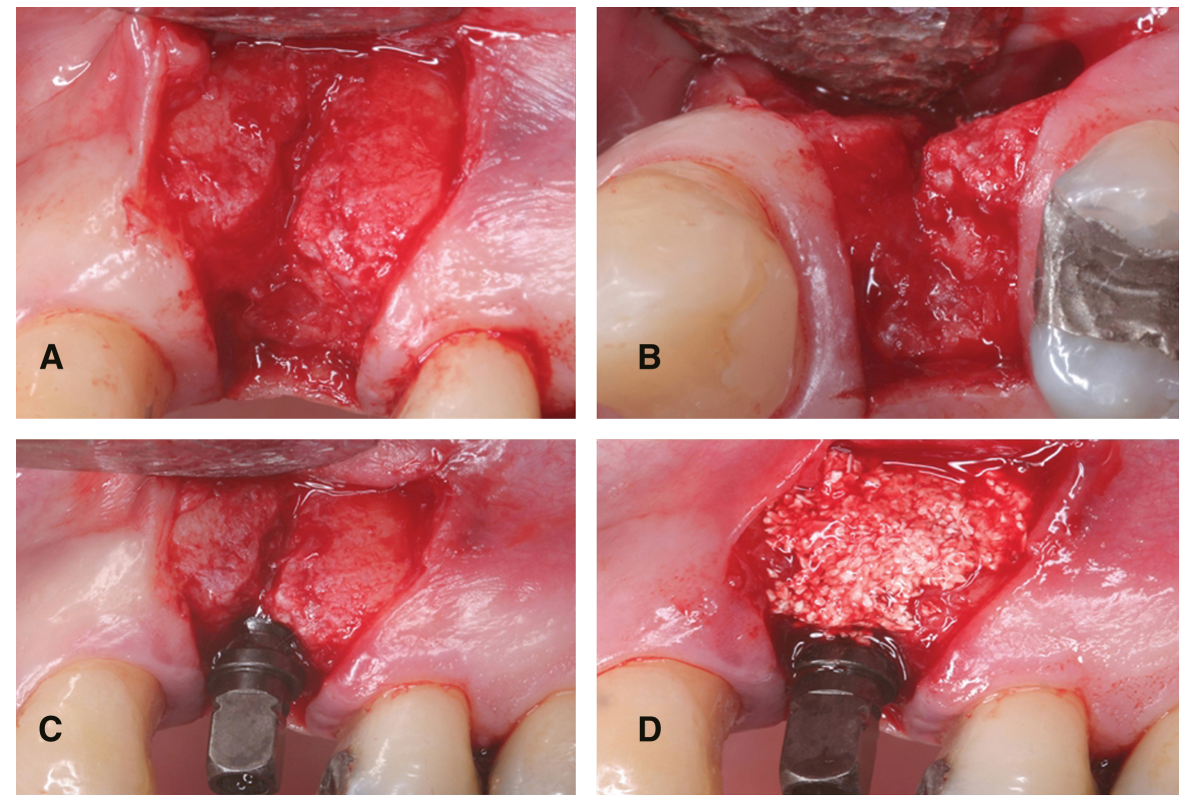

Buccal (A) and occlusal (B) views of incipient defect observed in control sites. C) Defect became associated with the implant. D) Defect grafted with Putty PI 5.
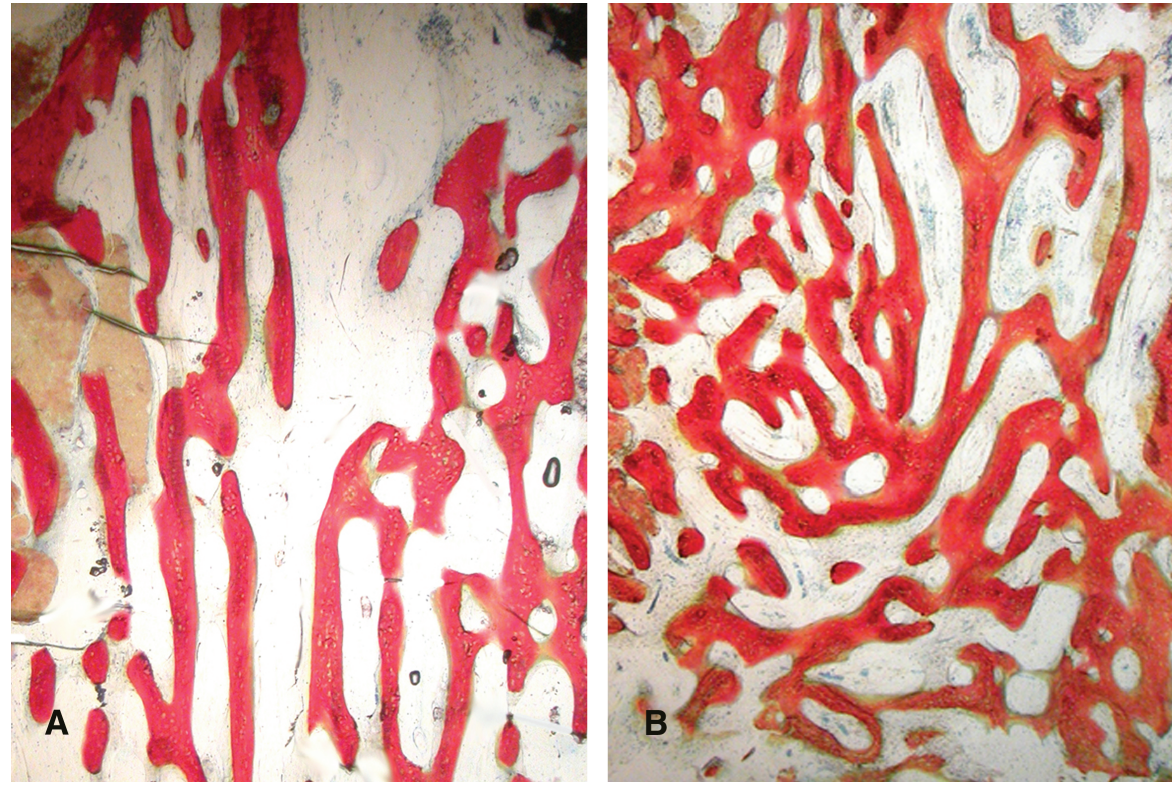

A) Vertically organized trabeculae seen in control sites. B) Thick, mature, and organized trabeculae observed in sites treated with Putty P I5. (Original magnification $\times 100$.) 
record pre- and post-treatment ridge dimensions were not able to fully represent the behavior of test and control sites in terms of alveolar ridge width during the course of the study. Because the post-treatment measurement accounted for the widest portion of the ridge, this measurement did not record areas of incipient ridge atrophy for 33\% of the control sites (Fig. 3). These incipient defects required bone grafting at the time of implant placement. No test sites presented this type of ridge deficiency, emphasizing the importance of alveolar ridge preservation. It also is important to consider that these incipient defects were observed only 4 months after tooth extraction.

Histomorphometric analyses of core biopsies retrieved from grafted and control sites at the time of implant placement revealed interesting results. Similar percentages of vital bone were found in both groups. Because healing of extraction sockets happens from the socket walls, it could be assumed that grafted sites should have a smaller percentage of vital bone toward the center of the core compared to non-grafted sites. This assumption was not confirmed, probably because of the fast replacement of the graft particles by new bone. This phenomenon, which is not seen commonly in other types of defects, might be explained by the greater healing potential of extraction sockets. The similar percentages of bone marrow and fibrous tissue found between the groups could be due to the reduced amount (mean: 6.25\%) of residual Putty P15 particles observed. This significantly low percentage of residual particles is consistent with a previous study ${ }^{56}$ and could be attributed to the small particle size of this xenograft as well as the lower packing density related to the putty's consistency. However, a more detailed analysis of the pattern of trabeculation revealed that control sites tended to present vertically oriented bone trabeculae, whereas test sites tended to show more organized and better distributed bone trabeculae (Fig. 4). It can be hypothesized that although control sites underwent the natural healing process, during which osteogenesis followed the usual pattern of migration from the socket walls, the presence of Putty P15 in test sites may have guided initial osteogenesis to achieve more mature patterns of trabeculation sooner. Furthermore, less postoperative discomfort was reported at 14 days by subjects who were treated with Putty P15, which might have been due to the enhanced wound stability achieved with bone grafting.

Another example of the positive effects of alveolar ridge preservation for implant dentistry was observed in this study. Future studies including larger sample sizes and other grafting protocols are encouraged to further explore the effects of extraction socket augmentation using Putty P15 and/or other bone-grafting protocols in preserving alveolar ridge dimensions.

\section{ACKNOWLEDGMENTS}

This study was supported by DENTSPLY Friadent Ceramed, Lakewood, Colorado. The authors report no conflicts of interest related to this study.

\section{REFERENCES}

1. Bays RA. The pathophysiology and anatomy of edentulous bone loss. In: Fonseca RJ, Davis WH, eds. Reconstructive Preprosthetic Oral and Maxillofacial Surgery. Philadelphia: W.B. Saunders; 1986:1-17.

2. Cardaropoli G, Araujo M, Hayacibara R, Sukekava F, Lindhe J. Healing of extraction sockets and surgically produced - augmented and non-augmented - defects in the alveolar ridge. An experimental study in the dog. $J$ Clin Periodontol 2005;32:435-440.

3. Sevor JJ, Meffert R. Placement of implants into fresh extraction sites using a resorbable collagen membrane: Case reports. Pract Periodontics Aesthet Dent 1992;4:35-41.

4. Werbitt MJ, Goldberg PV. The immediate implant: Bone preservation and bone regeneration. Int $J$ Periodontics Restorative Dent 1992;12:206-217.

5. Bragger U, Hammerle CHF, Lang NP. Immediate transmucosal implants using the principle of guided tissue regeneration (II). A cross-sectional study comparing the clinical outcome 1 year after immediate to standard implant placement. Clin Oral Implants Res 1996; 7:268-276.

6. Howell TH, Fiorellini J, Jones A, et al. A feasibility study evaluating rhBMP-2/absorbable collagen sponge device for local alveolar ridge preservation or augmentation. Int J Periodontics Restorative Dent 1997; 17:124-139.

7. Artzi Z, Nemcovsky CE. The application of deproteinized bovine bone mineral for ridge preservation prior to implantation. Clinical and histological observations in a case report. J Periodontol 1998;69:1062-1067.

8. Artzi Z, Tal H, Dayan D. Porous bovine bone mineral in healing of human extraction sockets. Part 1: Histomorphometric evaluations at 9 months. J Periodontol 2000;71:1015-1023.

9. Ashman A, Lopinto J. Placement of implants into ridges grafted with bioplant HTR synthetic bone: Histological long-term case history reports. J Oral Implantol 2000; 26:276-290.

10. Froum S, Orlowski W. Ridge preservation utilizing an alloplast prior to implant placement - Clinical and histological case reports. Pract Periodontics Aesthet Dent 2000;12:393-402.

11. Froum S, Cho SC, Rosenberg E, Rohrer M, Tarnow D. Histological comparison of healing extraction sockets implanted with bioactive glass or demineralized freezedried bone allograft: A pilot study. J Periodontol 2002; 73:94-102.

12. Wang HL, Kiyonobu K, Neiva RF. Socket augmentation: Rationale and technique. Implant Dent 2004;13: 286-296.

13. Nevins M, Mellonig JT. Enhancement of the damaged edentulous ridge to receive dental implants: A combination of allograft and the Gore-Tex membrane. Int $J$ Periodontics Restorative Dent 1992;12:96-111.

14. Iasella JM, Greenwell H, Miller RL, et al. Ridge preservation with freeze-dried bone allograft and a collagen membrane compared to extraction alone for 
implant site development: A clinical and histologic study in humans. J Periodontol 2003;74:990-999.

15. Zubillaga G, von Hagen S, Simon BI, Deasy MJ. Changes in alveolar bone height and width following post-extraction ridge augmentation using a fixed bioabsorbable membrane and demineralized freeze-dried bone osteoinductive graft. J Periodontol 2003;74:965-975.

16. Becker $W$, Urist $M$, Becker BE, et al. Clinical and histologic observations of sites implanted with intraoral autologous bone grafts or allografts. 15 human case reports. J Periodontol 1996;67:1025-1033.

17. Luczyszyn SM, Papalexiou V, Novaes AB Jr., Grisi MF, Souza SL, Taba $M$ Jr. Acellular dermal matrix and hydroxyapatite in prevention of ridge deformities after tooth extraction. Implant Dent 2005;14:176-184.

18. Cammack GV 2nd, Nevins M, Clem DS 3rd, Hatch JP, Mellonig JT. Histologic evaluation of mineralized and demineralized freeze-dried bone allograft for ridge and sinus augmentations. Int $J$ Periodontics Restorative Dent 2005;25:231-237.

19. Araujo MG, Lindhe J. Dimensional ridge alterations following tooth extraction. An experimental study in the dog. J Clin Periodontol 2005;32:212-218.

20. Araujo MG, Sukekava F, Wennstrom JL, Lindhe J. Ridge alterations following implant placement in fresh extraction sockets: An experimental study in the dog. $J$ Clin Periodontol 2005;32:645-652.

21. Lekovic V, Camargo PM, Klokkevold PR, et al. Preservation of alveolar bone in extraction sockets using bioabsorbable membranes. J Periodontol 1998;69: 1044-1049.

22. Löe H. The gingival index, the plaque index and the retention index systems. $J$ Periodontol 1967;38: Suppl.:610-616.

23. Misch CE, Hoar J, Beck G, Hazen R, Misch CM. A bone quality-based implant system: A preliminary report of stage I E stage II. Implant Dent 1998;7:35-42.

24. Marx RE, Snyder RM, Kline SN. Cellular survival of human marrow during placement of marrow-cancellous bone grafts. J Oral Surg 1979;37:712-717.

25. Urist MR, Granstein R, Nogami H, Svenson L, Murphy R. Transmembrane bone morphogenesis across multiplewalled diffusion chambers. New evidence for a diffusible bone morphogenetic property. Arch Surg 1977;112: 612-619.

26. Burwell RG. Osteogenesis in cancellous bone grafts: Considered in terms of cellular changes, basic mechanisms and the perspective of growth-control and its possible aberrations. Clin Orthop 1965;40:35-47.

27. Feinberg SE, Fonseca RJ. Biologic aspects of transplantation of grafts. In: Fonseca RJ, Davis WH, eds. Reconstructive Preprosthetic Oral and Maxillofacial Surgery. Philadelphia: W.B. Saunders; 1986.

28. Schallhorn RG. The use of autogenous hip marrow biopsy implants for bony crater defects. J Periodontol 1968;39:145-147.

29. Goldberg VM, Stevenson S. Natural history of autografts and allografts. Clin Orthop Relat Res 1987;225:7-15.

30. Russell JL. Grafton demineralized bone matrix: Performance consistency, utility, and value. Tissue Eng 2000;6:435-440.

31. Buck BE, Malinin TI, Brown M. Bone transplantation and human immunodeficiency virus: An estimate of risk-acquired immunodeficiency syndrome (AIDS). Clin Orthop 1989;240:129-134.

32. Buck BE, Resnick L, Shah SM, Malinin TI. Human immunodeficiency virus cultured from bone. Implica- tions for transplantation. Clin Orthop 1990;251:249. 253.

33. Quattlebaum JB, Mellonig JT, Hensel NF. Antigenicity of freeze-dried cortical bone allograft in human periodontal osseous defects. J Periodontol 1988;59:394-397.

34. Guizzardi S, Di Silvestre M, Scandroglio R, Ruggeri A, Savini R. Implants of heterologous demineralized bone matrix for induction of posterior spinal fusion in rats. Spine 1992;17:701-707.

35. von Arx T, Cochran DL, Hermann JS, Schenk RK, Buser D. Lateral ridge augmentation using different bone fillers and barrier membrane application. A histologic and histomorphometric pilot study in the canine mandible. Clin Oral Implants Res 2001;12:260-269.

36. An HS, Simpson JM, Glover JM, Stephany J. Comparison between allograft plus demineralized bone matrix versus autograft in anterior cervical fusion. A prospective multicenter study. Spine 1995;20:2211-2216.

37. Mellonig JT. Decalcified freeze-dried bone allograft as an implant material in human periodontal defects. Int $J$ Periodontics Restorative Dent 1984;4(6):40-55.

38. Gazdag AR, Lane JM, Glaser D, Forster RA. Alternatives to autogenous bone graft: Efficacy and indications. J Am Acad Orthop Surg 1995;3:1-8.

39. Schwartz Z, Mellonig JT, Carnes DL Jr., et al. Ability of commercial demineralized freeze-dried bone allograft to induce new bone formation. J Periodontol 1996;67: 918-926.

40. Bhatnagar R, Qian J, Gough C. The role in cell binding of a $\beta$-bend within the triple helical region in collagen a1(I) chain: Structural and biological evidence for conformational tautomerism on fiber surface. J Biomol Struct Dyn 1997;14:547-560.

41. Vastardis S, Yukna RA, Mayer ET, Atkinson BL. Periodontal regeneration with peptide-enhanced anorganic bone matrix in particulate and putty form in dogs. J Periodontol 2005;76:1690-1696.

42. Yeung RW, Jin LJ, Pang M, Pow E. Human histologic and electromicroscopic analysis with synthetic peptide enhanced hydroxyapatite in the maxillary sinus elevation procedure: A case report. Implant Dent 2005; 14:237-241.

43. Turhani D, Cvikl B, Watzinger E, et al. In vitro growth and differentiation of osteoblast-like cells on hydroxyapatite ceramic granule calcified from red algae. J Oral Maxillofac Surg 2005;63:793-799.

44. Thorwarth M, Schultze-Mosgau S, Wehrhan F, et al. Bioactivation of an anorganic bone matrix by P-15 peptide for the promotion of early bone formation. Biomaterials 2005;26:5648-5657.

45. Krauser JT, Rohrer MD, Wallace SS. Human histologic and histomorphometric analysis comparing OsteoGraf/ $\mathrm{N}$ with PepGen P-15 in the maxillary sinus elevation procedure: A case report. Implant Dent2000;9:298-302.

46. Smiler DG. Comparison of anorganic bovine mineral with and without synthetic peptide in a sinus elevation: A case study. Implant Dent 2001;10:139-142.

47. Sogal A, Tofe AJ. Risk assessment of bovine spongiform encephalopathy transmission through bone graft material derived from bovine bone used for dental applications. J Periodontol 1999;70:1053-1063.

48. Becker W, Becker BE, Caffesse R. A comparison of demineralized freeze-dried bone and autologous bone to induce bone formation in human extraction sockets. $J$ Periodontol 1994;65:1128-1133.

49. Lance EM. Some observations on bone graft technology. Clin Orthop 1985;200:114-124. 
50. Claflin RS. Healing of disturbed and undisturbed extraction wounds. J Am Dent Assoc 1936;6:945-959.

51. Booker BW 3rd, Loughlin DM. A morphologic study of the mesial root surface of the adolescent maxillary first bicuspid. J Periodontol 1985;56:666-670.

52. Lekovic V, Kenney EB, Weinlaender M, et al. A bone regenerative approach to alveolar ridge maintenance following tooth extraction. Report of 10 cases. $J$ Periodontol 1997;68:563-570.

53. Nevins M, Camelo M, Paoli S, et al. A study of the fate of the buccal wall of extraction sockets of teeth with prominent roots. Int $J$ Periodontics Restorative Dent 2006;26:19-29.

54. Vance GS, Greenwell H, Miller RL, Hill M, Johnston H, Scheetz JP. Comparison of an allograft in an experimental putty carrier and a bovine-derived xenograft used in ridge preservation: A clinical and histologic study in humans. Int J Oral Maxillofac Implants 2004;19:491-497.
55. Vasilic N, Henderson R, Jorgenson T, Sutherland E, Carson $\mathrm{R}$. The use of bovine porous bone mineral in combination with collagen membrane or autologous fibrinogen/ fibronectin system for ridge preservation following tooth extraction. J Okla Dent Assoc 2003;93:33-38.

56. Thompson DM, Rohrer MD, Prasad HS. Comparison of bone grafting materials in human extraction sockets: Clinical, histologic, and histomorphometric evaluations. Implant Dent 2006;15:89-96.

Correspondence: Dr. Rodrigo Neiva, Department of Periodontics and Oral Medicine, School of Dentistry, University of Michigan, 1011 N. University, Rm. 3323B, Ann Arbor, MI 48109-1078. Fax: 734/763-5503; e-mail: rneiva@ umich.edu.

Submitted January 20, 2007; accepted for publication September 1, 2007. 